\title{
Dietary implications in acetylsalicylic acid intolerance
}

\author{
Statement by the Food Allergy Working Group of the German Society for \\ Allergology and Clinical Immunology (DGAKI)
}

\author{
Sabine Dölle-Bierke · Sibylle Plank-Habibi · Christiane Schäfer · Birgit Ahrens · Barbara Ballmer-Weber · \\ Kirsten Beyer · Katharina Blümchen · Isidor Huttegger · Uta Jappe · Jörg Kleine-Tebbe · Lars Lange · \\ Susanne Lau · Ute Lepp · Vera Mahler · Sabine Müller · Joachim Saloga · Sabine Schnadt · Zsolt Szepfalusi • \\ Regina Treudler · Anja Wassmann-Otto · Thomas Werfel · Torsten Zuberbier · Imke Reese · Margitta Worm
}

Received: 13 November 2019 / Accepted: 5 December 2019 / Published online: 11 May 2020

(c) The Author(s) 2020

The authors S. Dölle-Bierke, S. Plank-Habibi, C. Schäfer,

I. Reese and M. Worm contributed equally to the manuscript.

S. Dölle-Bierke · T. Zuberbier · Prof. Dr. M. Worm $(\bowtie)$ Department of Dermatology, Venereology, and Allergology, Charité - Universitätsmedizin Berlin, Berlin, Germany margitta.worm@charite.de

S. Plank-Habibi

Vital Clinic, Alzenau, Germany

\section{Schäfer}

Nutritional Therapy, Allergology \& Gastroenterology,

Schwarzenbek, Germany

B. Ahrens · V. Mahler

Clinical Allergology Section, Paul-Ehrlich Institute, Langen,

Germany

\section{B. Ballmer-Weber}

Allergology Research and Teaching, Department of

Dermatology, University Hospital Zürich, Zurich,

Switzerland

Allergology Section, Department of Dermatology, Cantonal Hospital St. Gallen, St. Gallen, Switzerland

\section{B. Ahrens · K. Beyer $\cdot$ S. Lau}

Department of Pediatric Pulmonology, Immunology, and Intensive Care Medicine, Charité - Universitätsmedizin Berlin, Berlin, Germany

\section{K. Blümchen}

Department of Allergology, Pulmonology, and Cystic

Fibrosis, Department of Pediatric and Adolescent Medicine,

University Hospital Frankfurt, Frankfurt am Main, Germany

\section{Huttegger}

Pediatric Allergology and Pulmonology, University Medical

Center for Pediatric and Adolescent Medicine, Paracelsus

Private Medical University, Salzburg Regional Hospitals,

Salzburg, Austria

\section{U. Jappe}

Research Center Borstel, Leibniz Lung Center, Airway Research Center North (ARCN), Member of the German Center for Lung Research (DZL), Borstel, Germany Interdisciplinary Allergy Outpatient Department, Department of Medicine III, University Hospital Schleswig-Holstein, Lübeck Campus, Lübeck, Germany

J. Kleine-Tebbe Westend Allergy and Asthma Center, Berlin, Germany

\section{Lange}

St. Marien Hospital, Bonn, Germany

U. Lepp

Pulmonary Medicine, Allergology, Dr. Lepp Practice, Buxtehude, Germany

\section{Mahler}

Medical Faculty, Friedrich-Alexander University

Erlangen-Nürnberg, Nuremberg, Germany

\section{S. Müller}

Department of Dermatology and Venereology, University of Freiburg Faculty of Medicine, Albert-Ludwig University Freiburg, Freiburg, Germany

\section{J. Saloga}

Department and Outpatient Department of Dermatology, University Hospital Mainz, Mainz, Germany

\section{S. Schnadt}

German Allergy and Asthma Association (DAAB), Mönchengladbach, Germany

\section{Z. Szepfalusi}

Department of Pediatrics and Adolescent Medicine, Medical University Vienna, Vienna, Austria 


\section{Summary}

Background Acetylsalicylic acid (ASA) may cause difficult-to-treat symptoms of the airways, skin, or gastrointestinal tract in hypersensitive patients. Due to the chemical relationship between salicylic acid and ASA, a role of a low-salicylate diet has been discussed. Methods This review evaluates whether low salicylate diets are meaningful from an allergological or nutritional-physiological perspective.

Results The body's arachidonic acid metabolism plays a crucial role in the pathogenesis of ASA intolerance. Despite their chemical affinity, ASA and salicylic acid affect the arachidonic pathway differently. The intake of salicylic acid with food is low compared to therapeutic doses of ASA. There is increasing evidence that protective effects of a high fruit and vegetables diet is related in part to the intake of salicylates. In salicylatelow diets, fruit and vegetables are reduced, harboring the risk of an insufficient diet and malnutrition. Conclusion Dietary therapy in ASA-intolerant patients is not recommended.

Keywords Salicylic acid · ASA · COX · Antiinflammatory diet · Aspirin

$\begin{array}{ll}\text { Abbreviations } \\ \text { AERD } & \text { Aspirin-exacerbated respiratory disease } \\ \text { ASA } & \text { Acetylsalicylic acid } \\ \text { COX } & \text { Cyclooxygenase } \\ \text { DAMP } & \begin{array}{l}\text { Damage-associated molecular pattern } \\ \text { molecule }\end{array} \\ \text { HMGB1 } & \text { Human high mobility group box 1 } \\ \text { NSAID } & \text { Non-steroidal anti-inflammatory drugs }\end{array}$

Intolerance to acetylsalicylic acid (ASA) is based on a non-IgE-mediated hypersensitivity reaction. In hypersensitive patients, ASA can trigger symptoms of the skin/mucosa as well as the respiratory and gastrointestinal tract. In its most severe form, ASA intolerance can manifest in the airways as Samter's triad. The latter refers to a combined onset of ASA intolerance (intolerance to non-steroidal anti-inflammatory

\section{R. Treudler}

Department of Dermatology, Venereology, and Allergology, Leipzig Interdisciplinary Allergy Center, University Hospital Leipzig, Leipzig, Germany

\section{A. Wassmann-Otto}

Dermatological Outpatient Clinic, Hamburg, Germany

\section{T. Werfel}

Department of Immunodermatology and Experimental Allergology, Department of Dermatology, Allergology, and Venereology, Medical University Hannover, Hannover, Germany

\section{Reese}

Nutrition Counseling and Therapy with Special Focus on Allergology, Munich, Germany drugs [NSAID]), nasal polyps and bronchial asthma [1, 2]. The term aspirin-exacerbated respiratory disease (AERD) is more recently used for the respiratory form of disease. ASA intolerance is caused by alterations in the arachidonic acid metabolism, followed by an imbalance of eicosanoids formed from arachidonic acid [3].

Oxidative degradation of arachidonic acids takes place through two enzyme systems: the lipoxygenase and the cyclooxygenase (COX) pathway. ASA mainly effects the COX-1 degradation pathway and causes impaired immunological homeostasis with an increased production of pro-inflammatory eiconsoids, primarily leukotrienes and prostaglandin $\mathrm{E}_{2}$, and can promote an accumulation of immunological effector cells (mast cells and eosinophils among others) [4-6].

ASA is a chemical compound that does not occur naturally. Nevertheless, some foods contain its parent substance, salicylic acid, a phenolic acid belonging to the secondary plant substances and possessing anti-inflammatory properties [7]. The relationship between the two substances has given rise to a discussion on whether the natural salicylic acid content in food should be taken into account for difficult-to-treat ASA intolerance. However, there is no scientific evidence as yet that dietary salicylic acid is relevant in the pathogenesis of ASA intolerance [8].

The main sources of salicylates in foods include alcoholic beverages, herbs, spices, fruit, fruit juice, tomato-based sauces and vegetables. Therefore, a reduction of the dietary intake of salicylates is necessarily associated with a high carbohydrate and protein diet. The increased consumption of cereals and cereal products, milk and milk products, meat, eggs, and fish that often results from this dietary change harbors a clear risk of an insufficient diet.

As such, a reduction in dietary salicylates would have a significant impact on the basic diet, an impact that cannot be justified from the perspective of nutritional science. The salicylate intake in a regular diet is around $3-5 \mathrm{mg} /$ day, which is comparable with the intake of other secondary plant substances [9, 10]. Despite the good bioavailability of dietary salicylates, serum levels are far below the triggering threshold dose shown in studies for ASA [11, 12]. Moreover, even at pharmacological concentrations, salicylic acid has no direct effect on either COX-1 or COX-2, in contrast to ASA [13]. However, by binding to a newly identified protein (human high mobility group box 1 [HMGB1]) belonging to the group of alarmins (damage-associated molecular pattern molecule [DAMP]), salicylic acid and its derivatives can indirectly affect COX-2 and also inhibit the production of pro-inflammatory cytokines [14].

The intake of salicylates as part of a diet high in fruit and vegetables is rather associated with major health benefits. Efforts are underway to include salicylic acid as an essential vitamin: "vitamin S" [13-20]. 


\section{Conclusion}

The recommendation to reduce dietary salicylates to treat ASA intolerance has no pathophysiological background. In contrast, such a reduction poses the risk of dysnutrition. Nutritional therapy should aim for a diet high in vegetables. This ensures the supply of antioxidants, trace elements, as well as secondary plant and mineral substances. An increased intake of eicosapentaenoic acid and docosahexaenoic acid in fish (oil) at the same time as reducing the intake of arachidonic acid can have a favorable effect on fat intake.

Funding Open Access funding provided by Projekt DEAL.

Conflict of interest J. Kleine-Tebbe has received grants and/or honoraria from AllergenOnline (Nebraska, USA), Allergy Therapeutics, Allergopharma, ALK-Abelló, AstraZeneca, personal fees from Bencard, Dr. Pfleger, GSK, HAL Allergy, InfectoPharm, LETI, Lofarma, Novartis, Merck US, Sanofi Genentech, Stallergenes-Greer, Springer International Publishers, ThermoFisher Scientific, and Thieme Publishers, Germany. He has also received support (non-financial) from the American Academy of Allergy Asthma and Immunology, the European Academy of Allergy and Clinical Immunology, and the WHO/IUIS Allergen nomenclature subcommittee. He has received honoraria and support (non-financial) from the German Society for Allergology and Clinical Immunology-all outside the present work. S. Lau has received honoraria from ALK, DBV, Sanofi Genzyme and Allergopharma, outside the present work. U. Lepp has received honoraria from Chiesi, ALK-Abelló, Bencard Allergie, Novartis Pharma GmbH, Grifols, MedaPharm, and CGC-Cramer, outside the present work. S. Müller has received honoraria from Novartis $\mathrm{GmbH}$ and Bencard $\mathrm{GmbH}$, outside the present work. R. Treudler has received grants and/or honoraria from Sanofi-Genzyme, ALK-Abelló, Takeda, Novartis, and the Hautnetz Leipzig. R. Treudler also declares a scientific collaboration with and financial compensation from the Fraunhofer-IZI Leipzig-all outside the present work. M. Worm has received lecture fees, was active as a consultant and member of the advisory board, and has given lectures for the following companies: Mylan Germany, ALK-Abelló Arzneimittel, Allergopharma GmbH \& Co. KG, HAL Allergie, Stallergenes $\mathrm{GmbH}$, and Bencard Allergie, outside the present work. T. Zuberbier declares that he is active for the WHO initiative "Allergic Rhinitis and Its Impact on Asthma" (ARIA), the German Society for Allergology and Clinical Immunology (DGAKI), the European Centre for Allergy Research Foundation (ECARF), the Global Allergy and Asthma European Network (GA2LEN), the Committee on Allergy Diagnosis and Molecular Allergology, and the World Allergy Organization (WAO). S. Dölle-Bierke, S. Plank-Habibi, C. Schäfer, B. Ahrens, B. Ballmer-Weber, K. Beyer, K. Blümchen, I. Huttegger, U. Jappe, L. Lange, V. Mahler, J. Saloga, S. Schnadt, Z. Szepfalusi, A. Wassmann-Otto, T. Werfel and I. Reese declare that they have no competing interests.

Open Access This article is licensed under a Creative Commons Attribution 4.0 International License, which permits use, sharing, adaptation, distribution and reproduction in any medium or format, as long as you give appropriate credit to the original author(s) and the source, provide a link to the Creative Commons licence, and indicate if changes were made. The images or other third party material in this article are included in the article's Creative Commons licence, unless indicated otherwise in a credit line to the material. If material is not included in the article's Creative Commons licence and your intended use is not permitted by statutory regulation or exceeds the permitted use, you will need to obtain permission directly from the copyright holder. To view a copy of this licence, visit http://creativecommons.org/licenses/by/4.0/.

\section{References}

1. Klimek L. ASS-Intoleranz-Syndrom: Aktuelle Optionen der Therapie. Dtsch Arztebl. 2017;114:28-33.

2. Park H, Choi Y, Jung CG, Park HS. Potential biomarkers for NSAID-exacerbated respiratory disease. Mediators Inflamm. 2017;2017:8160148.

3. Wedi B. Aktuelle Diagnostik der NSAR-Überempfindlichkeit. Allergo J.2017;26:204-11.

4. May A, Weber A. Azetylsalizylsäure und Polyposis nasi. Allergo J.2007;16:113-7.

5. Mitchell JA, Akarasereenont P, Thiemermann C, Flower RJ, Vane JR. Selectivity of nonsteroidal antiinflammatory drugs as inhibitors of constitutive and inducible cyclooxygenase. Proc Natl Acad Sci U SA. 1993;90:11693-7.

6. Umbreit C, Virchow JC, Thorn C, Hormann K, Klimek L, Pfaar O. Analgetikaintoleranz: Ein häufiges, interdisziplinäres Krankheitsbild [Aspirin-Intolerance-Syndrom: a common and interdisciplinary disease]. Internist (Berl). 2010;51:1196-201.

7. Malakar S. Bioactive food chemicals and gastrointestinal symptoms: a focus of salicylates. J Gastroenterol Hepatol. 2017;32(Suppl 1):73-7.

8. Plank-Habibi S, Dölle S, Schäfer C. Diätetische Implikationen: Salicylsäure und ASS-Unverträglichkeit. Allergologie. 2018;41:261-72.

9. Watzl B. Einfluss sekundärer Pflanzenstoffe aufdieGesundheit. 12. Ernährungsbericht. Bonn: DGE; 2012. pp.355-74.

10. Wood A, Baxter G, Thies F, Kyle J, Duthie G. A systematic review of salicylates in foods: estimated daily intake of a Scottish population. Mol Nutr Food Res. 2011;55(Suppl 1):S7-S14.

11. Blacklock CJ, Lawrence JR, Wiles D, Malcolm EA, Gibson IH, Kelly CJ, et al. Salicylic acid in the serum of subjects not taking aspirin. Comparison of salicylic acid concentrations in the serum of vegetarians, non-vegetarians, and patients takinglow dose aspirin. JClin Pathol. 2001;54:553-5.

12. Paterson JR, Srivastava R, Baxter GJ, Graham AB, Lawrence JR. Salicylic acid content of spices and its implications. JAgric Food Chem. 2006;54:2891-6.

13. Xu XM, Sansores-Garcia L, Chen XM, Matijevic-Aleksic N, Du M, Wu KK. Suppression of inducible cyclooxygenase 2 gene transcription by aspirin and sodium salicylate. Proc Natl Acad Sci USA. 1999;96:5292-7.

14. Choi HW, Tian M, Song F, Venereau E, Preti A, Park SW, et al. Aspirin's active metabolite salicylic acid targets high mobility group box 1 to modulate inflammatory responses. Mol Med. 2015;21:526-35.

15. Dempsey DA, Klessig DF. How does the multifaceted plant hormone salicylic acid combat disease in plants and are similar mechanisms utilized in humans? BMC Biol. 2017;15:23.

16. Duthie GG, Wood AD. Natural salicylates: foods, functions and disease prevention. Food Funct. 2011;2:515-20.

17. Lawrence JR, Baxter GJ, Paterson JR. Aspirin for cancer is no mere antiplatelet prototype. There is potential in its ancient roots. Med Hypotheses. 2016;94:74-6.

18. Morgan G. 'Salicylic acid deficiency' has important public health implications. Eur J Public Health. 2003;13:283. 
19. Rinelli S, Spadafranca A, Fiorillo G, Cocucci M, Bertoli S, Battezzati A. Circulating salicylic acid and metabolic and inflammatory responses after fruit ingestion. Plant Foods Hum Nutr. 2012;67:100-4.

20. SivagnanamP, Koutsoumpas A, ForbesA. Respiratorysymptoms in patients with inflammatory bowel disease and the impact of dietary salicylates. Dig Liver Dis. 2007;39:232-9. 